Article

\title{
Bio-Based Products in the Automotive Industry: The Need for Ecolabels, Standards, and Regulations
}

\author{
Simone Wurster * and Luana Ladu \\ Department of Innovation Economics, Technische Universität Berlin (TU Berlin), 10623 Berlin, Germany; \\ luana.ladu@tu-berlin.de \\ * Correspondence: simone.wurster@tu-berlin.de
}

Received: 29 November 2019; Accepted: 11 February 2020; Published: 21 February 2020

\begin{abstract}
At the Hanover Fair in April 2018, the Bioconcept-Car was presented as a model for the future of sustainable mobility. Likewise, a car made of cellulose nanofiber was presented at the Tokyo Motor Show in 2019. Various additional automotive applications for bio-based materials have been developed, some of which are already in use in cars. However, supportive measures for stimulating their market acceptance are needed. Based on a mix of research methods, this article describes how ecolabels, sustainability standards, and regulations might support the market uptake of bio-based car components. In addition, comparison with three other types of bio-based products are provided. The article ends with suggestions for future market development activities.
\end{abstract}

Keywords: sustainability; bio-based products; automotive industry; ecolabels; cars

\section{Introduction}

\subsection{Rationale for this Article}

At the Hanover Fair in April 2018, the Bioconcept-Car was presented as a model of the future of sustainable mobility. The Bioconcept-Car is a race car, in which various traditional components are replaced with ones made of bio composite materials and which has been successfully tested in races. Converted for racing and powered by a low-emission rapeseed biodiesel, this Volkswagen (VW) combines innovative approaches to lightweight construction in the mobility sector based on resource-saving materials, such as natural fiber reinforced composites, bio-based resins, and bio-based plastics (see [1]). Likewise, a car made of cellulose nanofiber (CNF) was presented at Tokyo Motor Show in 2019, which was created at the Kyoto university. Currently, a number of automakers are investigating CNFs feasibility for mass production [2]. Various additional automotive applications for bio-based materials have been identified, some of which are already in use in cars. However, supportive measures are needed to stimulate the development of the market for these components. This article analyzes possible instruments to support their market uptakes.

\subsection{Novelty of this Research}

By building consumers' awareness on environmental issues and by influencing consumers' behavior, ecolabels can be used to stimulate market development. This is particularly the case of ISO 14024 Type I environmental label (e.g., the EU Ecolabel), which provides consumers with third party verified information on environmental related attributes of the products, which cannot be easily evaluated by the consumers.

By providing access to this information, ecolabels aim at supporting consumers in taking well-informed purchasing decisions thus increasing the market of more environmentally responsible products. There is no research on ecolabels regarding cars and car components yet. The authors of [3] 
in reference to other sectors show this gap specifically. With a specific focus on Europe, this article describes how ecolabels, sustainability standards, and regulation might support the market uptake of bio-based car components. Emphasis is put on bio-based solutions for the interior of cars, doors, and similar components. In addition, comparisons with three other sectors of bio-based products, insulation material, food packages, and mulch film are provided. In this context, we will also show that the need for bio-based products regarding the introduction of new ecolabels is different. With regards to insulation materials, for example, the interviewees referred to established labels and suggested extensions and updates instead of the introduction of new labels.

The research was conducted within the European project STAR-ProBio (see in particular [4,5] with regards to research on ecolabels, standards, and regulations). The content was updated and supplemented by additional findings of the German project ConCirMy (Configurator for the Circular Economy), funded by the German Ministry of Education and Research.

\section{Materials and Methods}

\subsection{Core Research Elements}

\subsubsection{Bio-based Automotive Applications}

In 2010, an average car consisted of approximately $150 \mathrm{~kg}$ of plastic and plastic composites and approximately $1160 \mathrm{~kg}$ of iron and steel. Plastics are used, for example, for the interior, seating, bumpers, exterior, electrical components, etc. Moreover, natural and synthetic rubber is used in car tires (see [6]). A number of automotive applications for bio-based materials have been identified, partly already in use. According to [7], the term bio-based product refers to products wholly or partly derived from biomass. Examples for bio-based automotive applications include bio resins, fiber-based solutions for the interior parts, composite materials, and organic sheets (see, e.g., [6]). Bio-based polyurethanes have started to replace fossil-based foams while bio-based polyamides also have the potential to replace petrochemical alternatives (see, e.g., [6], p. 30 and related sources).

This article discusses three automotive applications in particular: (a) Side doors with interior cladding of composite materials using natural fibers such as flax, hemp, linen, and a bio-based resin; (b) mirror covers and turn signal covers made of bio-based polyamides; and (c) car interiors made of Polypropylene combined with natural fibers. An advantage of the interior parts is that their functional requirements are lower compared to exterior ones. A new field of application for bio-based materials in the automobile industry are tires, which the newly launched ConCirMy project aims to analyze. Car tires with a high share of bio-based content are already being developed.

\subsubsection{Ecolabels}

The international standards organization ISO defines a label as a "tag, brand, mark, pictorial or other descriptive matter, written, printed, stenciled, marked, embossed or impressed on, or attached to the packaging or container of a finished manufactured product" (ISO 21371:2018 (en), 3.1, [8]). Labelling can address many aspects of sustainability, including, for example, environmental sustainability, social sustainability, social and animal welfare, as well as safety and health.

An important category of labels are ecolabels, defined as "seals of approval given to products that are deemed to have fewer impacts on the environment than functionally or competitively similar products" [9]. They address the growing global concern for environmental protection. ISO distinguishes between three types of ecolabels: Type I: Environmental labels according to ISO 14024 (classic ecolabel, based on multicriteria sets covering the entire life cycle of a product and requiring thresholds); Type II: Environmental claims according to ISO 14021 (self-declared certification); and Type III: Environmental Product Declarations (EPDs) of the environmental quality of a product according to ISO 14025 (see [10]) (single criterion based on LCA, but that does not provide thresholds). 
According to [11,12], ecolabels have diverse positive effects on various stakeholder categories. For example, manufacturers are "increasingly demanding proof of their products', environmental soundness in order to prevent future liability or negative publicity". In addition, by building consumers' awareness on environmental issues and by influencing consumers' behavior, ecolabels can be used to stimulate market development. In general, ecolabel criteria are set so that only a small percentage of products in a product category (typically, $5 \%$ to $30 \%$ ) can meet these criteria.

In addition to stimulating market development, eco-labels can also promote innovation. In this context, reference [13] provides findings regarding "green innovation," referring to innovative products, which meet at least partly environmental or social criteria. Based on a literature review, reference [13] emphasizes that " $(\mathrm{I}) \mathrm{t}$ is possible to generate green innovation if the labelling scheme is very selective" in order to assure that very few products get the ecolabel without innovation. However, challenges have to be considered as well: "When labels do not induce green innovation ( ... ) they might increase environmental spill overs, increasing overall production, or decreasing the share of green goods."

An overview of ecolabels suitable for bio-based products is provided by the Fachagentur Nachwachsende Rohstoffe e. V. [14]. However, the majority of the relevant ecolabels refer to textiles, cosmetics, wood products, and biodegradable products, while the automotive sector needs further research. An interesting approach outside Europe is provided by the US BioPreferred Program, managed by the US Department of Agriculture (USDA), which combines specific guidance for public procurers with a labelling initiative to encourage the purchase of bio-based products.

\subsubsection{Formal Standards}

Standards are documents, "established by consensus and approved by a recognized body, that provides, for common and repeated use, rules, guidelines or characteristics for activities or their results, aimed at the achievement of the optimum degree of order in a given context" ([15], definition 3.2). In this context, the authors of [16] use the specified form "formal standards" and highlight the characteristics "developed in recognized standardization bodies", "voluntary and consensus driven."

Standards can promote the diffusion of new products in various ways. The authors of [17] refer, for example, to quality aspects, health, and safety, which are relevant in the given context. Based on the EU mandate M/429, the European Committee for Standardization (CEN) established a standardization program for bio-based products. Consequently, in 2011 CEN's Technical Committee (TC) 411 was created. Its scope comprises horizontal aspects of the bioeconomy, including a common terminology, methods for determining bio-based content in a product, Life Cycle Assessments (LCA), sustainability of biomass and guidance on the use of existing standards for the end-of-life options (see [18]).

Based on the European standardization mandates (M/491) and M/492 ([19,20]), TC 411 has been developing standards to help specific sectors move towards higher renewable biomass content. In addition to that technical committee, other CEN TCs deal with specific bio-based products and applications. For example, CEN/TC 249 is responsible for the development of standards for biopolymers and TC 19 is tasked with creating standards for bio-based lubricants while CEN/TC 383 works on European standards establishing sustainability criteria for biofuels (see [21] for further details). However, bio-based car components are not yet considered specifically.

\subsubsection{Regulatory Framework}

Regulatory framework conditions have been identified as "important factors influencing the innovation activities of companies, industries and whole economies" [22]. Regulations are "mandatory legal restrictions released and enacted by the government" [16]. This includes also common regulations developed by representatives of EU member states' governments. The regulatory framework is "generally composed of regulations enforced by governmental institutions" while "industry and other affected stakeholders may complement these governmental regulations by self-regulatory coordination" [16]. 
In contrast to regulations, formal standards are, as mentioned, "developed in recognized standardization bodies" and "are voluntary and consensus driven" ([16] based on ISO/IEC, 2004). In addition to this clear distinction, legislation can adopt standards that then become enforceable by regulation. In addition, there are specific interdependencies of the two instruments in the course of the so called "New Approach" (see [16]), discussed later in this section.

According to [23], "regulation can be an important influence on the direction of innovation" and can help to "overcome organizational inertia, foster creative thinking and mitigate agency problems." The authors of [22] highlight that environmental regulations have caused the emergence of new industries, such as the "environmental industry", which is characterized by technologies to protect the environment or cause less environmental damage. In general, the impact of regulation on innovation depends on the extent of the compliance cost and the incentive effect. As the diagram of technological progress or innovation (i) and capital intensity (k) in Figure 1 shows, there is a positive impact on the rate of technical progress $\left(i_{1}\right)$, if compliance costs are low or even zero and the incentives are positive. As shown by $i_{2}$, referring to lower technical progress than $i^{*}$ with the same capital intensity, the impact is negative, especially with high compliance cost and low or even negative innovation incentives.

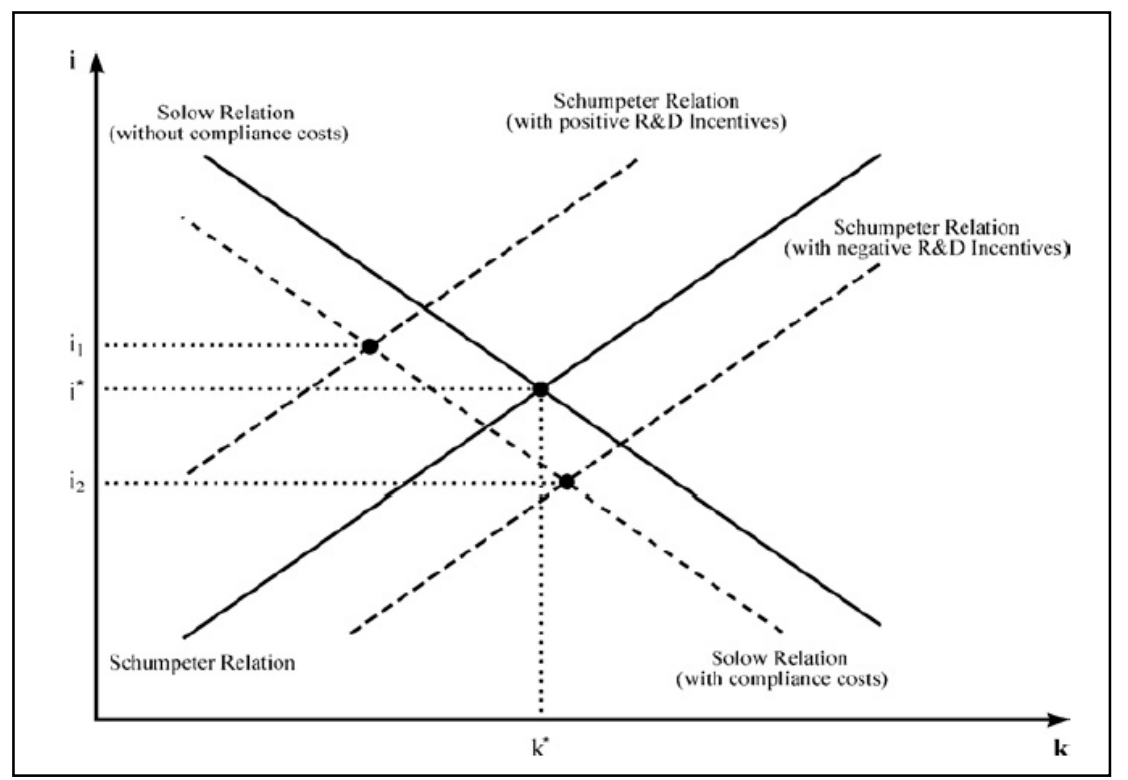

Figure 1. The influence of regulation on the endogenous determination of innovation. Source: Reference [22] based on a figure of Nicolas Crafts.

In this context, [16] also highlights the importance to distinguish between two research streams: The first one "intensively discusses regulation (in any form) strictly as it relates to environmental issues" while the second stream "investigates regulation outside of the environmental field and considers regulation as a possible barrier to innovation." An example for such barriers is provided by the managers interviewed by [24], who indicated that "environmental regulation amounted to a significant net cost to (their companies)." In addition to this finding, the second research stream as a whole "[ ... ] often neglects self-regulatory instruments" [16] and their potential positive contributions.

Addressing the different findings from the two research streams, [16] conducted further research on the "optimal policy interventions to foster and support innovation" based on an analysis in low and high uncertain markets. They found for low uncertain markets, that regulations have a positive influence on the firm's innovation efficiency. However, highly uncertain markets are often characterized by an unstable and fast changing technical environment and, usually, higher information asymmetries, thus increasing the probability of a potential misfit between regulations and the underlying market technologies. Since regulations are developed in top-down legislative processes, this potential misfit is a typical risk of regulatory instruments. In contrast to this, formal standards are derived from a process 
driven mainly by the market (i.e., firms) and are therefore, as [16] found, more closely connected to the requirements of the underlying technology. As a result, regulation has a negative impact on a firm's innovation efficiency in highly uncertain markets while the effect of standards is positive.

The market for bio-based products is emerging. More specifically, it is embedded in a transition process in the sociotechnical regime, aimed at reaching a paradigm shift away from the traditional fossil-based economy towards a more sustainable economy with products of biological origin (see, e.g., $[25,26])$. The current low level of stability in the market is also linked with a low level of certainty (see, e.g., [25]). For this reason, implementing regulations currently faces challenges on the market-but provides also opportunities to reduce this uncertainty with clear guidance. The challenges themselves can be addressed by regulations, which adopt formal standards and the so-called "New Approach" [27]. The "New Approach" to harmonization and standardization, initiated in 1985 is "an attempt to accelerate both harmonization processes at the Council level and European standardization processes at industry level while at the same time providing more flexibility for innovation and easier market access" [28]. Around a third of European standardization activities are developed to directly support the implementation of European policies [29]. The Lead Market Initiative (LMI) is another demand-side policy directed at stimulating markets for bio-based products (see [21]).

The development of public strategies and other efforts to stimulate the bioeconomy in the EU aims to achieve technological leadership and tangible improvement in Europe's social, economic and environmental welfare (EU Bioeconomy Strategy, [30]). The authors of [31] describe the regulatory landscape for sustainable bio-based products based on the analysis of 50 key documents at European and Member State levels. The analysis showed that there is an increasing reference to sustainability requirements and sustainability criteria, supported by certification and labels. According to [31], the policies with direct influence on the bio-based industry mostly tackle single and specific sustainability issues/sectors with high public interest (e.g., biofuels, genetically modified organisms (GMOs), forestry, waste, etc.). Framework Directives also play an important role by laying down key principles applying to any product in a specified context. This article considers specifically the Renewable Energy Directive (RED) and the EU Waste Framework Directive (WFD).

The RED [32] is an example for an approach, where public regulations recognize private initiatives, such as voluntary certification schemes, as a way to prove compliance with mandatory criteria. In this regard, certification schemes and labels beyond the biofuel sectors could be potentially used to show compliance with sustainability criteria. Precondition for this is the official recognition of the scheme or label by the EU. The so called RED II applying after 2021 will expand sustainability criteria to all sectors of bioenergy.

The WFD [33] addresses the end of life stage of products and promotes the waste hierarchy as a guiding principle. This hierarchy sets out a preference for waste prevention, followed by the sequence reuse, recycling, recovering energy, and finally landfill.

\subsection{Research Goals and Methodologies}

The Ecolabel Index [34] shows the importance of Ecolabels worldwide. In this context, specific goals were formulated for biobased products in Europe: "Additionally and building upon the availability of guidance and training materials for bio-based products in procurement for different product groups, specific requirements promoting bio-based materials and products could be included during the development of EU Ecolabel and Green Public Procurement (GPP) criteria for new or other existing product groups not yet addressed and further innovative procurement activities. "[30] Likewise, the STAR4BBI project highlighted the need to develop sustainability certification for all products and identified the EU Ecolabel as a relevant tool for showing sustainability [35]. The automotive sector has not been considered appropriately in this context so far.

In response to technical developments towards sustainability in the automotive sector, we aimed to explore how ecolabels, improvements in the regulatory frameworks and standards could support the market uptake of bio-based car components. In addition, we wanted to provide insight to what extent 
this set of suggested measures is similar or different compared to other product sectors. For this purpose, we conceptualized and implemented a research strategy with five elements: 1. Literature review, 2. analysis of the existing ecolabels landscape, 3. preparation, conduct and analysis of expert interviews in four areas of bio-based products, 4 . deriving comparisons between the automotive industry and other sectors and 5. development of recommendations for ecolabel criteria, standardization and the regulatory framework, which were developed in an iterative process.

A problem of bio-based products in general is the lack of evidence of their specific environmental, social and economic sustainability, for which the development of tools and indicators is of high relevance. An initial goal of our research was therefore to identify suitable ecolabel criteria. By means of the Ecolabel Index [34], which provides information on 465 ecolabels from 99 countries and 25 industry sectors, we identified the most relevant labels for bio-based products.

Suitable labels were selected by using the following search terms in the Ecolabel Index: "bio" (52 hits), "bio-based" (2 hits), "biobased" (2 hits), "sustainable" (34 hits), "construction" (24 hits), "building" (62 hits), "waste" (29 hits), and "plastics" (4 hits). Based on further screenings, we analyzed 42 ecolabels (see Figure 2), including, for example the EU Ecolabel, the German Blue Angel, the Carbon Trust Footprint Label, and the Nordic Swan regarding relevant basic criteria. Detailed information on all labels are provided in the Appendix A.

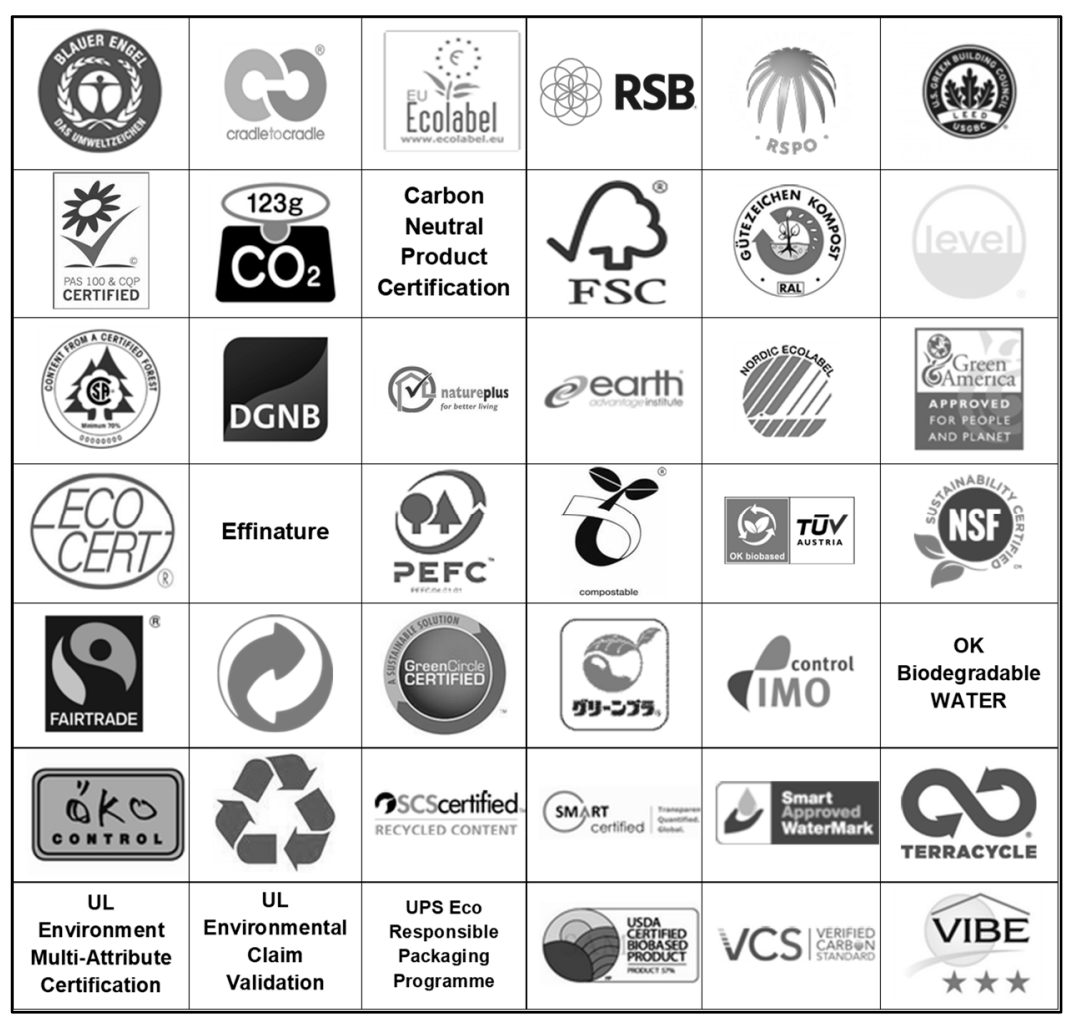

Figure 2. Selected ecolabels for bio-based products.

In depth analyses of these labels' criteria were conducted based on the label descriptions taken from the labels' website. An Excel template shown in Table 1 was created for this purpose.

Four researchers were involved in the analyses. Based on an analysis of all 42 Excel tables, the findings were summarized. Section 3 will provide a summary of these relevant existing criteria in selected ecolabels, which are grouped as follows (see also [4]):

(a) Sustainability criteria: Environmental, social and economic criteria.

(b) Additional criteria: Percentage of bio-based content and fitness for use. 
Table 1. Template for the analysis of ecolabels.

\begin{tabular}{cccccc}
\hline \multicolumn{7}{c}{ Label: XYZ } \\
\hline $\begin{array}{c}\text { Product } \\
\text { categories }\end{array}$ & $\begin{array}{c}\text { Bio-based criteria } \\
\text { and indicators }\end{array}$ & $\begin{array}{c}\text { Environmental } \\
\text { criteria and indicators }\end{array}$ & $\begin{array}{c}\text { Social criteria } \\
\text { and indicators }\end{array}$ & $\begin{array}{c}\text { Economic criteria } \\
\text { and indicators }\end{array}$ & $\begin{array}{c}\text { Revision } \\
\text { process }\end{array}$ \\
\hline
\end{tabular}

This research paved the way for the development of an interview guide to be used in the in-depth case study analysis. We carried out semi-structured interviews [36] with professionals dealing with the automotive industry and the three additional product groups of our analysis.

The interview guide consisted of six sections: background of the interviewee(s), framework conditions, ecolabels, sustainability standards, regulatory framework conditions, and policy gaps. In addition to open questions, a section included a list of criteria identified in the analysis of the ecolabel landscape in order to rank their importance in sustainability analysis Interviewees were selected to represent a wide range of stakeholders (see Table 2).

Table 2. Overview of participants to the interview series.

\begin{tabular}{|c|c|c|c|c|}
\hline Stakeholder Group & Producers, Retailers etc. & $\begin{array}{l}\text { Certification Bodies, Testing } \\
\text { Laboratories, Standards Bodies }\end{array}$ & Procurement & $\begin{array}{l}\text { Other (Government, } \\
\text { Research) }\end{array}$ \\
\hline Interviewees in total & 10 & 3 & 6 & 3 \\
\hline
\end{tabular}

Our research of the automotive industry consisted of interviews of five target groups. They included representatives of: A big car manufacturer, a big automotive supplier, a governmental agency and a research institute, as well as experts specialized in automotive field tests. The governmental agency had a specific focus on bio-based car components while the core competencies of the research institute included bio-based materials and materials for automotive applications in particular.

Our analysis started with discussions on PBS (Polybutylene Succinate) and PLA (Polylactic Acid) (See Appendix 3 of [4] for details on both materials) applications in the automotive sector. While the industry's experience with PBS is still limited, different material related issues were highlighted by the interviewees in the discussions on automotive PLA applications. For example, PLA material's reaction to differences in temperature and humidity are current challenges that require further research. For this reason, our scope was broadened to include bio-based car components in general. Car components made of composite materials were specifically considered as they have certain attractive properties, for example regarding their energy balance.

The interviews took place between May and September 2018. The results were supported by the analysis of additional sources provided by the interviewees. Based on all the gathered information, we finally developed a set of recommendations supporting the use of sustainable car components, enriched by a comparison with the other three cases.

Section 3, consisting of Sections 3.1-3.3, presents the results of the research steps 2 to 4 described above: The analysis of the existing ecolabel landscape, the expert interviews and the comparisons of the automotive industry and other sectors. Recommendations for the development of ecolabel criteria, standardization, and the regulatory framework based on the results of step 5 are presented in Section 4 . 


\section{Results}

\subsection{Analysis of the Existing Ecolabels Landscape}

An ecolabel is an important vehicle to communicate to consumers the benefits of bio-based products, especially if predefined sustainability criteria are met and verified by means of a certification process [21]. This is especially the case for product attributes that the consumer cannot evaluate, such as its environmental impact. Sustainability claims of environmental labels and declarations are usually granted upon proven satisfaction of preselected criterion/criteria. This is for example the case of ISO 14000 ecolabels, (see Section 2.1.2). Based on the analysis of different ecolabels, this paper identified criteria in the three pillars of sustainability: Economic, social and environmental. An additional criterion, related to product characteristics and performances was added (see Figure 3).

\begin{tabular}{|c|c|c|}
\hline \multicolumn{3}{|c|}{ Selected criteria for each sustainability pillar } \\
\hline $\begin{array}{c}\text { Environmental: } \\
\text { Sustainable sourcing } \\
\text { of biomass, GHG } \\
\text { emission, Toxicity, } \\
\text { End-of-Life criteria }\end{array}$ & $\begin{array}{c}\text { Economic: } \\
\text { Energy efficiency of the production } \\
\text { stage, Biomass utilization efficiency, Life } \\
\text { cycle cost }\end{array}$ & $\begin{array}{c}\text { Social: } \\
\text { Working } \\
\text { conditions of } \\
\text { the employees, } \\
\text { Food security }\end{array}$ \\
\hline & Fitness for use, Bio-based content \\
\hline
\end{tabular}

Figure 3. Identified assessment criteria.

\subsubsection{Selected Criteria for the Environmental Pillar}

\section{Sustainable Sourcing of Biomass}

An important aspect to be considered in the sustainability assessment of bio-based products is the sustainable sourcing of biomass. An interesting document in this context is the RED, which has established clear, legally binding requirements on sustainable sourcing of biomass for bioenergy, liquid biofuels and bioliquids. The main sustainability requirements included in the RED are:

- Greenhouse gas emission saving from the use of biofuels and bioliquids shall be at least $50 \%$ compared to fossil fuels $(60 \%$ for biofuels produced in plants whose operation started after 1 January 2017) (see [37]).

- (Sustainable) biofuels and bioliquids shall not be made from raw material obtained from land with high biodiversity.

- (Sustainable) biofuels and bioliquids shall not be made from raw material obtained from land with high carbon stock (such as wetlands or forests).

The RED provides incentives to biofuels that show compliance with these environmental sustainability requirements. The material use of biomass is not incentivized in the same way. Indeed, regulation/sustainability certification for material use of bio-based raw materials is missing in Europe [38]. Nevertheless, the sustainability of biomass for material use is important and some pioneer labels deal with sustainable sourcing in the assessment of bio-based products, for example the Roundtable on Sustainable Biomaterials (RSB). The RSB Principles and Criteria (RSB-STD-01-001) include twelve principles: 1. Legality, 2. Planning, Monitoring and Continuous Improvement, 3. Greenhouse Gas Emissions, 4. Human and Labor Rights, 5. Rural and Social Development, 6. Local 
Food Security, 7. Conservation, 8. Soil, 9. Water, 10. Air, 11. Use of Technology, Inputs and Management of Waste, and 12. Land Rights. According to principle 7 on conservation, operations shall avoid negative impacts on biodiversity, ecosystems and conservation values. In addition, it is important to mention three certificates, which include relevant sustainability principles: International Sustainability and Carbon Certification (ISCC), PLUS and FSC®/PEFC (see STAR Pro-Bio, 2018a). PEFC also includes social criteria and requires that genetically modified organisms are not used.

Emissions of Greenhouse Gas (GHG)

The pollution of air is an important aspect considered in sustainability assessment of products and processes. In this regard, the measurement of GHG emissions is often used as a proxy to measure the impact of a product or process on climate change. GHG emissions are also accounted for a life cycle perspective and used in various Type III labels, such as the Carbon Trust Footprint Label. Accordingly, the Ecolabel Index includes 25 ecolabels that focus on the carbon footprint of products or processes. Different options are available for measuring GHG emissions (see [4]) and the comparability among the different approaches is difficult, because they often consider different impact categories. Different studies show that the use of biomass in products may help reduce the global warming potential of our economy. The authors of [39], for example, have shown that various bio-based products have the advantage of a lower $\mathrm{CO}_{2}$ footprint during production compared to alternative fossil-based products.

Toxicity

According to [40], the term toxicity refers to the ability of a substance to produce an adverse effect upon a living organism. The importance of reduced human toxicity from the perspective of the users is, for example, shown by [41]. Various labels consider human toxicity as a criterion (e.g., different categories of the EU Ecolabel and the ÖkoControl label (source: Internal ecolabel database). In addition, other labels, such as the Ecolabel, consider toxicity to aquatic organisms.

\section{End-of-Life Criteria}

The importance of end-of-life criteria for consumers interested in more sustainable products is shown by various studies, e.g., [42]. Depending on product properties and what substances they may contain, a number of end-of-life options can be considered for bio-based products. Given the partial or total biological origin of bio-based products, their end-of-life management can be important as to avoid losing materials that can more naturally be returned to biological cycles. Indeed, the waste hierarchy encourages the prevention of waste or the return of materials into the economy, which has to be considered specifically in the prioritization of end-of-life options. However, it is also important to note that not all biologically sourced materials can be added to biological cycles.

\subsubsection{Selected Criteria for the Economic Pillar}

As described in Section 2.1.2, ecolabels are mainly seals that show environmental impacts of products. However, our analysis unveiled social and economic criteria used for assessing sustainability in the current ecolabel landscape. Some of the identified and proposed economic criteria, such as energy efficiency and biomass utilization efficiency are closely linked to the environmental pillar. Under the economic criteria, life cycle cost is briefly introduced and considered as a specific horizontal issue, which will be further described in Section 3.1.5.

Energy Efficiency of the Production Stage

While economic criteria are rarely considered by ecolabels, the Cradle to Cradle $₫$ concept considers the use of materials, energy, and water in the production. The production stage of bio-based products can provide various advantages compared to fossil-based products. Based on the example of smart drop-ins, the authors of [43] highlight that the production of bio-based products may require 
significantly less energy in comparison to fossil-based products. To show this advantage appropriately, the consideration of a specific criterion on the energy efficiency of the production process is suggested. Specific advantages of bio-based products could be shown by a criterion, which compares the energy consumption with a conventional benchmark product.

\section{Biomass Utilization Efficiency}

The biomass utilization efficiency (BUE) factor was developed by [44]. It is defined as "percentage of initial biomass ending up in the end product based on the molar mass of the reactant (= biomass) and target bio-based product."

The biomass utilization efficiency was also identified as a specific assessment gap by [45]. According to the previous section, the Cradle to Cradle®scheme considers the use of materials in the production. In this context, attractive options to include assessment criteria to highlight advantages of specific bio-based products exist. The authors of [44] found, for example, that the bio-based polyester PLA (Polylactic Acid) and the acid SA (Succinic Acid) exhibit a highly efficient material use of biomass. The examples show the attractiveness of a BUE criterion. This was further analyzed in our in-depth case analysis, presented in Section 3.2.

\section{Life Cycle Cost}

An additional economic criterion is Life Cycle Cost (LCC). According to [46], LCC is a method for evaluating all relevant costs over time of a project, product or measure. It takes into account: Initial costs (including capital investment costs, purchase, and installation costs); future costs (including energy costs, operating costs, maintenance costs, capital replacement costs, financing costs); and any resale, salvage, or disposal cost over the lifetime of the project, product or measure [47]. Bio-based products can provide various cost advantages. The Cradle to Cradle $\AA$ concept combines environmental, social and specific economic analysis, adding that "in the medium term the goal is for designs that are positive or beneficial in terms of cost, performance, $(\ldots)$, and material (re)utilization potential with continuous use and reuse periods" [48]. Economic analysis focusing on LCC provide opportunities to highlight specific advantages of bio-based products. For example, the authors of [49] found that the LCC of ten environmental-friendly products are lower than those of traditional alternatives. LCC will be discussed further in Section 3.1.5 in a broader context.

\subsubsection{Selected Criteria for the Social Pillar}

The social pillar of sustainability addresses general social issues, as well as specific working conditions of the employees, who work in the various value chains of the entire life cycle of a bio-based product. An important social aspect to be considered is "food security", which is also mentioned as one of SCAR's five principles for the bioeconomy (see [50]) and considered, for example, by RSB. Furthermore, according to [51], the majority of the consumers worldwide regard it as extremely important that companies care for: safe drinking water as part of their products, services, or operations $(92 \%)$, health care $(87 \%)$, fair wages, and safe working conditions $(87 \%)$, as well as jobs and economic opportunity (86\%).

The majority of ecolabels have a strong focus on environmental aspects, compared to social and economic ones. Indeed, there are only few examples of ecolabels that include social criteria. One of them is the EU Ecolabel, which requires corporate social responsibility to respect "fundamental principles and rights at work" in the sets of assessment criteria for a few product categories. As described in the International Labour Organization's (ILO) Core Labour Standards, the UN Global Compact, and the OECD Guidelines for Multi-National Enterprises, such social standards should be observed by production sites along the supply chain of a product (see [52]). As another good practice example, PEFC does not only require food security (PEFC principle 6) but also to respect human and labor rights (principle 4), demanding: Freedom of workers to organize themselves and their representative and to negotiate with the employer, no forced and child labour, equal employment 
opportunities, equal treatment for all workers and working conditions that do not affect occupational safety or health (see [53]). The Cradle to Cradle®label considers the social impact of product cycles and production. The history of the RSPO certificate (see [54]) showed the importance of not only formulating social sustainability criteria but also of assessing compliance appropriately.

\subsubsection{Additional Criteria Related to Bio-based Characteristics and Performance}

\section{Bio-Based Content}

Bio-based products are partly or wholly made out of biomass. This is an important characteristic of these products that should be communicated to consumers. Some labels and standards require a minimum share of bio-based content. For example, the EU Ecolabel considers bio-based content in various product categories. Different methods are available for measuring the bio-based content, including: the bio-based carbon content methods, which measures the amount of renewable-based carbon in a given product, using the radiocarbon analysis (14C carbon approach). The specification CEN/TS 16137:2011 (Plastics—Determination of bio-based carbon content, [55]) expresses the bio-based carbon content as a fraction of the sample mass, or the total carbon/organic carbon content.

Fitness for Use

Functionality and performance are key product attributes. Therefore, various ecolabels include a 'fitness for use' criterion. According to [45], there are stakeholders, who are unsure about the performance of bio-based products, and in particular of their characteristics compared to conventional ones. Therefore, to facilitate comparisons with traditional fossil-based products, a criterion on functionality/performance could be of major importance to raise trust on bio-based products. The use of such a criterion could be voluntary and product-specific to keep labelling efforts as low as possible.

\subsubsection{Life Cycle Assessment}

Life cycle assessments (LCA) are "compilation(s) and evaluation(s) of the inputs, outputs and the potential environmental impacts of a product system throughout its life cycle" [56]. Their foundations are laid by the two general standards ISO 14040 and 14044, while EN 16760 describes how to handle the specificities of the bio-based part of a bio-based product in an LCA (see [57]). In particular, Environmental Product Declarations (EPDs), which are Type III labels according to the ISO classification, are a famous direct application of LCAs. Experts interviewed by [58] stressed that many bio-based products perform better than traditional alternative products over their entire life cycle, mostly in terms of important environmental impact categories (for example, end-of-life options and GHG emissions). However, currently existing ecolabels only relate to specific stages in the life cycle, for example, to the extraction/production of raw materials or the end-of-life. In addition, many labels only refer to environmental aspects, and not so much on social and economic issues (in particular LCC). The need for further research on LCA is fundamental considering that there are many open questions. As the project BioMat_LCA highlighted, at the moment no common LCA approach exists. Results vary a lot (see [59] for details). Harmonization and common calculation guidelines for LCAs are needed to avoid inconsistencies and contradicting results due to the use of different calculation methods.

\subsection{Results of the Expert Interviews and Related Research in the Automotive Industry}

\subsubsection{Ecolabels for Bio-Based Automotive Applications}

\section{General Considerations}

As an important prerequisite in the automotive sector, interviewees highlighted that certification can only take place with regards to single car components. Realizing an ecolabel for the category "bio-based vehicles" would not be possible because they consist of too many different materials and 
parts. Due to the newly introduced topic of bio-based car components, no specific ecolabels on sustainability and bio-based issues exist. Therefore, several labels with a more general focus are discussed as a starting point.

RSB and ISCC PLUS are regarded as important certificates to prove the sustainability of biomass. Limitations, in particular highlighted for ISCC PLUS, are that they do not refer to (car) components but just to the material. Furthermore, ISCC PLUS is not an ecolabel and its scope excludes, for example, end-of-life issues. Other general labels for bio-plastics mentioned in interviews are, for example, the end-of-life related labels from DIN CERTCO and Vincotte. In addition, the Blue Angel (Blauer Engel) label gained focus on bio-based plastics regarding recycling aspects. A general gap not addressed by the labels on plastics refers to bio-based cellulose fibers.

On the level of sustainability assessment criteria, it was highlighted that fuel consumption stays on the top of the lists of environmental characteristics, as fuel efficiency is a legal obligation in the automotive sector. Any material used for building a car has to support this goal. The weight of a car has a specific influence on its fuel consumption. Therefore, all suitable materials and components have to ensure that cars of an appropriate weight can be built.

Regardless of the existing solutions for selected specific questions, it was highlighted clearly that no ecolabel for bio-based automotive applications exists. One expert added: "Such a solution would be a 'super' output of STAR-ProBio to provide customers with transparent information." Explicitly, it was also mentioned that an EU-wide label such as the EU Ecolabel would be interesting for the automotive industry. Regarding the scope of a potential label, the importance to distinguish between different target groups was highlighted. Business-to-consumer (B2C) markets need labels, which are easy to understand, while issues, as for example LCA, are more important for business-to-business (B2B) markets.

The high number of options for the various car components is perceived as a challenge for the development of labelling specifications. An agreement on focusing on specific components by the car industry might be necessary. Currently, many areas of the market for bio-based car components are still in the testing stage. The test results will also play an important role in potential further steps regarding ecolabelling of car components.

\section{Ecolabel Criteria}

The interviewees views on selected sustainability assessment criteria are shown in Table 3, followed by an interpretation of the results.

Regarding bio-based content, the need for reference values (thresholds) facilitating comparisons was mentioned. However, it was suggested to appropriately consider the tradeoff between the origin of a feedstock and the minimum amount of bio-based content. If material with a higher percentage rate of bio-based content is only available abroad/outside Europe and requires more transportation efforts, this should also affect the environmental score.

Regarding sustainable biomass, experts drew our attention to two important general challenges regarding the use of bio-based materials in the automotive industry: Land use versus assurance of food security and the avoidance of GMOs. Regarding interior linings of car doors, for example, promising options to use material from residues were highlighted. Regarding GMOs, it was added by one of our interviewees that: "We could check where the seeds came from, but it would be too costly." Labelling could reduce such a cost. In general, the assessment criterion "sustainable biomass" is regarded as more suitable for B2B markets than for B2C markets. B2C markets would require detailed explanations of the concept. In a further discussion on the suitability of RED criteria it was mentioned that the use of bio-based products could be monitored by the following two specific principles: No conversion of land with previously high carbon stock and no use of raw materials obtained from land with high biodiversity such as primary forests or highly biodiverse grasslands. These aspects might be interesting issues that would specify the criterion "sustainable biomass" appropriately. 
As mentioned earlier, the origin of the material was another issue brought into the discussion. However, it was highlighted that the selection also depends on the availability of suitable material. An additional suggestion was to communicate the type of feedstock. Specifically, a label such as the Vincotte with a fix and a variable part was considered while the variable part could, for example, provide information on the raw material.

Table 3. Relevance of selected ecolabel criteria for bio-based car components.

\begin{tabular}{|c|c|c|c|}
\hline Assessment Criteria & Relevance for Ecolabels ${ }^{1}$ & Assessment Criteria & Relevance for Ecolabels \\
\hline $\begin{array}{c}\text { Sustainable } \\
\text { biomass/bio-based } \\
\text { content }\end{array}$ & 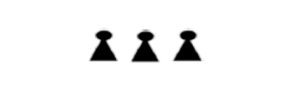 & Fundamental principles and rights at work & $\boldsymbol{\Sigma}$ \\
\hline $\mathrm{CO}_{2}$ emissions & $\boldsymbol{\Sigma} \Sigma$ & Energy requirement during production & 0 \\
\hline Toxicity & $\Sigma \Sigma \Sigma$ & Biomass utilization efficiency & \\
\hline End-of-life options & $\boldsymbol{\Sigma} \Sigma$ & Life cycle values & $\boldsymbol{\Sigma} \Sigma$ \\
\hline Fitness for use & 8 & Life cycle costs specifically & $8 \Omega$ \\
\hline $\begin{array}{l}\text { Corporate social } \\
\text { responsibility }\end{array}$ & $\boldsymbol{\Sigma}$ & & \\
\hline
\end{tabular}

Legend
nolevant in $>50 \%$ of the interviews
Note: Interviewees also made specific additional suggests for criteria, in particular related to land use and use of $50 \%$ of the interviews
water. ${ }^{1}$ Side doors with interior cladding of composite materials using natural fibers such as flax, hemp, linen, and
(a) bio-based resin; (b) mirror covers and turn signal covers made of bio-based polyamides/PPT; and (c) car interiors
made of Polypropylene combined with natural fibers.

$\mathrm{CO}_{2}$ emissions should be measured in the various life cycle stages including production, transport, use and end-of-life. Regarding the end-of-life stage in general, automotive applications require specific solutions. Recycling and incineration/energetic combustion are the key options. Regarding materials, which cannot be recycled, it was highlighted that energetic combustion must be preferred instead of incineration. Furthermore, it was pointed out that not only recyclability is important. The possibility to separate the bio-based parts is of particular importance. Other interviewees highlighted the need for energy as an important issue at this stage. They conducted a comparison between the disposal of carbon fibers, which requires significantly more energy than the disposal of bio-based fibers.

The need for the toxicity criterion is a specific one. Composite materials, which cannot be recycled, need to be incinerated or used for energetic combustion. For this reason, toxicity is a particular end-of-life issue for car components of these specific materials.

Specific discussions on the social criterion "fundamental principles and rights at work" led to the suggestion of an integration into the other social criterion "corporate social responsibility."

According to interviewees opinions, LCA, LCC (and also biomass utilization efficiency) are regarded as particular items for certificates for B2B markets; less for B2C markets. LCA information of bio-based automotive interior panels of various materials are, for example, provided by [60].

Car manufacturers are obliged to prepare energy footprint information for each vehicle and several experts stressed the potential usefulness of label information on LCA and LCC. However, it is likely that suppliers certify individual parts only, for which the creation of separate data might be difficult. A comparison for entire vehicles is regarded as challenging, since vehicles can exhibit many differences. Car components are also often exchangeable, which means that their lifetime differs 
from the lifetime of a "whole" car. For this reason, the realization of appropriate LCA and LCC show the need for further research. We were recommended to specify the number of LCA criteria under efficiency considerations. Specifically, it was suggested to consider the environmental criterion $\mathrm{CO}_{2}$ emissions only.

To summarize the findings in Table 3, key criteria for stakeholders of the automotive sector are sustainable biomass, $\mathrm{CO}_{2}$ emissions, end-of-life issues and social responsibility, added by LCAs with a specific focus on $\mathrm{CO}_{2}$ emissions. The interviewees also specified additional sustainability criteria, which they regard as important: The extent of water use (in the production); the use of energy beyond the production stage and the total use of nonrenewable energy.

The existence of bio-based materials leading to a weight reduction when replacing fossil-based materials was highlighted specifically. This weight reduction also implies petrol consumption savings which would justify an additional assessment criterion to highlight the advantages of bio-based car components compared to traditional components. However, only LCAs addressing cars as a whole would make this possible. A specific recommendation in this context referred to the facilitation of a classification of cars regarding energy issues, as well as fuel consumption (which is to be optimized also by characteristics of the material used in the production of the cars). Looking into the future, interviewees also regard aircraft and public transport with bio-based components as conceivable.

Solutions Suggested by Interviewees

Regarding ecolabels in general, the implementation of a program such as BioPreferred [61] was suggested. Specifically, a European register of bio-based products meeting selected sustainability criteria was proposed. The implementation of such a register of certified bio-based products could start with selected product categories only.

Regardless of having a national or European/international focus, the various existing private labels do not address the needs of the market appropriately according to expert opinion. An independent label is necessary. The development of one of the existing labels for such a solution would be interesting, but its realization at the member state level is regarded as difficult. Therefore, a European solution is suggested, at least for the public sector. Regarding an ecolabel for the automotive industry specifically, interviewees stressed the importance of the interest by (more) manufacturers for successfully establishing an ecolabel in the given area.

\subsubsection{Regulatory Measures to Support Bio-based Automotive Applications}

The current regulatory framework of bio-based car components includes, in particular, general end-of-life regulations for cars, e.g., the End-of-Life Vehicles Directive (Directive 2000/53/EC) and related national legislation such as the "Altautoverordnung" in Germany. Based on the directive, cars are dismantled and separated into their different materials. However, current European and national regulations are not specific enough for bio-based car components according to some interviewees. Examples in this regard refer to various life cycle stages: The development of components with appropriate characteristics, e.g., regarding recyclability, the use of energy for the production, and the requirement to minimize the number of residues. Issues of recycling have to be considered as well. They include, for example, questions on which material mix is possible and which bio-based material can be recycled together with fossil products. It is also considered important to involve recycling companies in these considerations. The usefulness of elements of the RED directive was discussed in particular. Table 4 summarizes the results.

Four different views were observed: 1 . These criteria are important; 2 . these criteria are important but could also be considered by a position paper of the car industry instead of a regulation; 3 . the adoption of the criteria is useful but the Member States shall have the opportunity to decide on the adoption individually on a national level; and 4. the "regulatory burden" should be kept as low as possible. 
As an example for the third view above, specific types of grassland were mentioned in interview C6, which could be replaced for the cultivation of renewable raw materials without negative consequences. The variety of the views requires further research. STAR-ProBio kept contact with the automotive industry in this regard.

Table 4. Relevance of criteria of the Renewable Energy Directive in the case study on bio-based car components.

\begin{tabular}{|c|c|c|c|c|c|}
\hline \multirow{2}{*}{ Element of the RED Directive } & \multicolumn{5}{|c|}{ Relevance for the Stakeholders } \\
\hline & $\mathrm{C} 1$ & $\mathrm{C} 2$ & $\mathrm{C} 3$ & $\mathrm{C} 4 / \mathrm{C} 5$ & C6 \\
\hline Greenhouse gas savings & No & $(\mathrm{x})$ & No (mainly an issue of fuels) & $x$ & $(\mathrm{x})$ \\
\hline $\begin{array}{l}\text { No use of areas converted from land } \\
\text { with previously high carbon stock }\end{array}$ & No & $(\mathrm{x})$ & \multirow{2}{*}{$\mathrm{No}^{1}$} & $x$ & $(\mathrm{x})$ \\
\hline $\begin{array}{l}\text { No use of raw materials obtained } \\
\text { from land with high biodiversity }\end{array}$ & No & $(x)^{2}$ & & $\mathrm{x}$ & $(x)^{3}$ \\
\hline
\end{tabular}

${ }^{1}$ Relevant but no need for further action because this is considered by ISCC PLUS already, ${ }^{2}$ the topics are regarded as relevant but a position paper of the car industry might be an instrument, which is regarded as to be more attractive for these stakeholders, ${ }^{3}$ see explanations in the text on exemptions.

An additional issue was raised within the interview topic "potential eco-label criteria on life cycle assessment and life cycle cost." The requirement of exemplary calculations by a European regulation was suggested. This would help show the advantages of bio-based products from cradle to grave and consider in particular the disadvantages of the disposal of carbon, which can be replaced by bio-based alternatives.

\subsubsection{Standards to Support Bio-based Automotive Applications}

As an important prerequisite for standardization considerations in the automotive sector, interviewees mentioned that this industry is an international one and needs common guidelines for production processes worldwide. There are various standards for materials traditionally used in this industry, for example, for steel and glass, addressing safety issues in particular. In addition, there are standards for composite materials, which apply to bio-based composites as well. Regarding sustainability issues of bio-based materials, the following standardization topics were discussed in the interviews: Life cycle assessment, sustainable material flows, reduction of energy use, use of renewable energy, minimization and appropriate use of residues, recyclability, social issues and life cycle cost. The desired guidance refers in particular to the use of energy, renewable energy specifically, the appropriate use of residues and recyclability while the complex specification of end-of-life measures may require an additional standard.

\subsection{Reflective Comparison of the Automotive Industry with other Bio-based Products}

As described in Section 1, our study on the automotive industry belongs to a series of four case studies, also including insulation material, food packages, and mulch film. As shown in Table 5, the results of the automotive industry deviate from all the other sectors in relation to three sustainability criteria.

In contrast to the automotive sector, the majority of the interviewees of the three other sectors suggested to include fitness for use and energy requirement during production in the criteria list of ecolabels for these products. Another contrast to the results from the automotive sector was that biomass utilization efficiency received support by at least $50 \%$ of the interviewees from the other industries/sectors.

The reason why most interviewees in the automotive sector suggested to exclude the item fit-ness for use from ecolabel criteria catalogues is that this issue is assessed much earlier in the life cycle of the car than ecolabelling takes place. Components, which do not meet necessary functionality 
requirements, are deselected early in the car design stage. By describing specific comparisons, it was also highlighted that the energy balance of bio-based composites is better than the one of an alternative carbon product. However, the different options to use renewable or nonrenewable energy would require considerations. Regarding the biomass utilization efficiency criterion, interviewees stressed that the high technical requirements, in particular on functional and exterior car components, determine clearly which material and biomass is suitable. The material with optimal BMU values does not necessarily have the characteristics/quality needed in the car industry. For this reason, the BMU criterion has a lower priority although it cannot be ignored. The criterion "fundamental principles and rights at work" was selected in the interviews on the other three areas of bio-based products while the deviation is a marginal one. Interviewees of the automotive sector confirmed the importance of this topic as well but suggested, for example, an assessment on the firm-level or the use of a composite criterion on social aspects.

Table 5. Relevance of selected ecolabel criteria in the case studies.

\begin{tabular}{|c|c|c|c|c|}
\hline \multirow{2}{*}{ Assessment Criteria } & \multicolumn{4}{|c|}{ Relevance for Ecolabels for the Case Study Products According to Interviews } \\
\hline & Bio-based Car Components ${ }^{1}$ & PLA/Food Packaging & Mulch Films & Insulation Materials \\
\hline $\begin{array}{c}\text { Sustainable } \\
\text { biomass/bio-based } \\
\text { content }\end{array}$ & 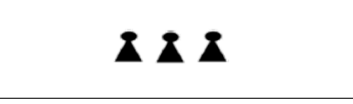 & 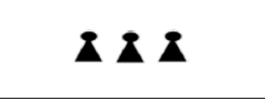 & $\mathbf{X} \mathbf{X}$ & $\mathbf{X X}$ \\
\hline $\mathrm{CO}_{2}$ emissions & 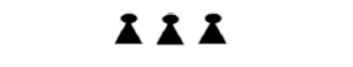 & 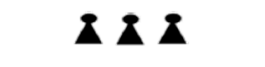 & 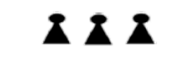 & 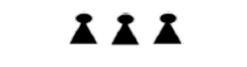 \\
\hline Toxicity & 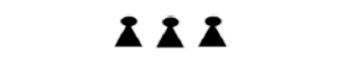 & 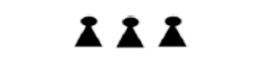 & $\mathbf{X X}$ & 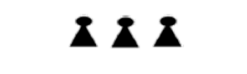 \\
\hline End-of-life options & $\Sigma \Sigma \Sigma$ & 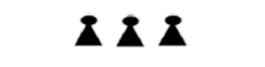 & 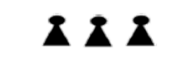 & 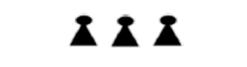 \\
\hline Fitness for use & 8 & 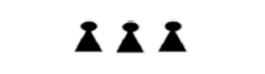 & 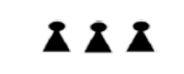 & 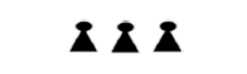 \\
\hline $\begin{array}{l}\text { Corporate social } \\
\text { responsibility }\end{array}$ & 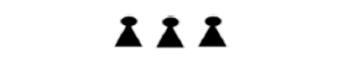 & 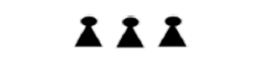 & 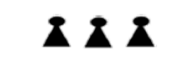 & 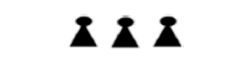 \\
\hline $\begin{array}{l}\text { Fundamental principles } \\
\text { and rights at work }\end{array}$ & $\boldsymbol{x}^{0}$ & 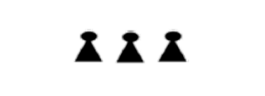 & 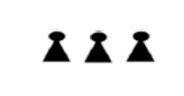 & 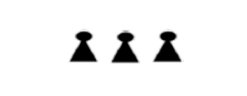 \\
\hline $\begin{array}{l}\text { Energy requirement } \\
\text { during production }\end{array}$ & $\boldsymbol{x}^{0}$ & $X \mathbf{X}$ & $X \mathbf{X}$ & 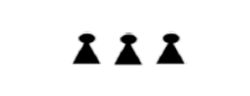 \\
\hline $\begin{array}{l}\text { Biomass utilization } \\
\text { efficiency }\end{array}$ & $\boldsymbol{\Sigma} \Omega$ & $X X$ & $\boldsymbol{\Sigma} \Omega$ & 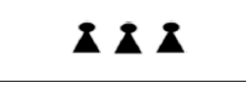 \\
\hline Life cycle values & 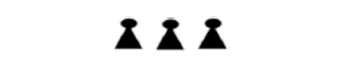 & $\boldsymbol{\Sigma} \boldsymbol{X}$ & 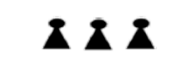 & $\boldsymbol{\Omega}$ \\
\hline $\begin{array}{l}\text { Life cycle costs } \\
\text { specifically }\end{array}$ & $\boldsymbol{\Sigma} \boldsymbol{X}$ & $\boldsymbol{\Sigma} \boldsymbol{X}$ & $\boldsymbol{\Sigma} \boldsymbol{x}$ & $\boldsymbol{\Sigma}$ \\
\hline \multirow{2}{*}{ Legend } & \multicolumn{2}{|c|}{$\underset{\text { relevant in }>50 \% \text { of the interviews }}{ }$} & \multicolumn{2}{|c|}{$\underset{\text { relevant in } 50 \% \text { of the interviews }}{ }$} \\
\hline & \multicolumn{2}{|c|}{${ }_{\text {not relevant in }>50 \% \text { of the interviews }}$} & \multicolumn{2}{|c|}{$\bigcirc_{\begin{array}{c}\text { alternatively, a suggestion for a modification } \\
\text { was made }\end{array}}$} \\
\hline
\end{tabular}

In addition to differences in the importance of the ecolabel criteria, there were also differences regarding the needs for new labels. While the positive response regarding labelling considerations for bio-based car components was described above, interviewees referred to existing labels with regards to insulation material and suggested updates and extensions of these labels only. 


\section{Discussion}

\subsection{Fulfilment of Our Research Goals and Summary of Findings}

This article aimed to provide suggestions for ecolabels, standards and regulations to support the market uptake of innovative bio-based cars and car components, currently under development in the automotive industry. On this basis, sustainability assessment gaps for these specific product groups were studied. A key finding is that existing ecolabels do not refer to bio-based car components and that a need to address this gap exists. This article unveiled key criteria, which are not only relevant for ecolabels but also for further standardization activities, although specific indicators and the establishment of related thresholds will require further research. We identified 11 ecolabel criteria, 10 of which are relevant for bio-based automotive components according to at least half of the interviewees. They include: Sustainable biomass/bio-based content, $\mathrm{CO}_{2}$ emissions, toxicity, end-of-life options, corporate social responsibility, fundamental principles and rights at work, energy requirement during production, biomass utilization efficiency, life cycle values, and life cycle costs specifically. Only the criterion "fitness for use" was deselected because this aspect is tested already in an early stage of the production process.

Options for a potential expansion of the European Ecolabel were also discussed. Focusing on the biomass specifically, an additional labelling gap regarding the assessment of bio-based cellulose fibers was identified.

In addition, regulatory measures to better integrate new characteristics relevant for bio-based products into existing regulations, covering their entire life cycle were proposed. Our interviewees also highlighted that current European regulations are not specific enough for the emerging field of bio-based car applications. Gaps refer, for example, to the development of the components, the recyclability and the requirement to minimize the number of residues. In addition, the development of exemplary LCAs and LCC for both bio-based and fossil-based products on a European level was suggested to show the advantages of bio-based materials. In particular bio-based car components, which facilitate a reduction of petrol consumption due to weight loss, are promising.

Last but not least, the development of a LCA standard for bio-based car components, specifically addressing the use of energy and the end-of-life stage was suggested, with recyclability as the key end-of-life aspect. The analysis also showed the importance to consider product-specific characteristics in the sustainability assessment of bio-based products and highlighted the need to customize sustainability assessment solutions for B2C and B2B markets, as well as public procurement.

In addition to its main focus on requirements to be considered by ecolabels, standards, and regulations to support bio-based car components better in the future, this article addressed various additional issues. In particular, it aimed to present specific needs of the automotive sector regarding ecolabels for bio-based products. It also explained why it might be useful to exclude criteria such as functionality and biomass utilization efficiency from sustainability assessment criteria sets in this context.

\subsection{Recommendations}

This paper recommends adding the category "bio-based automotive applications" in the EU Ecolabel, or at least to consider cellulose fiber materials in the labels on plastic. In this context, one expert stated: An eco-labelling solution "would be a 'super' output of STAR-ProBio to provide customers with transparent information." More research and communication with stakeholders on concreate ecolabelling measures are suggested to develop appropriate solutions.

Based on Section 3.2.3 and the desired guidance, in particular regarding the specification of end-of-life measures, which may require a separate standard, industry-driven considerations on standardization measures are suggested as well.

According to our discussions on regulatory measures, it should be specified, which bio-based materials can be recycled together with fossil products and which mix of car components is possible 
to facilitate appropriate recycling. It is also important to address the need for guidance to separate bio-based and non-bio-based parts appropriately in the end-of-life stage. An interesting observation in our analysis was that our interviewees' suggestions to address end of life issues included standardization measures and regulatory measures as well, while the differences were sometimes marginal. On this basis, more analyses are needed to use both instruments appropriately.

\subsection{Outlook}

This article aimed to provide suggestions for ecolabels, standards, and regulations to support the market uptake of bio-based cars and car components and to provide deeper insight in the needs of the bio-based economy based on three additional case studies.

The realization of a sustainable bio-based economy as a whole will rely on the commitment of the stakeholders. An intrinsic motivation to promote sustainability and a fundamental change on the demand side of the market is needed, as emphasized by our interviewees. The combination of suitable sustainability requirements and a change in society's mindset towards sustainability has the potential to become a cornerstone to make the sustainable bio-based economy a reality. In addition, [22] demonstrated how environmental regulation can lead to innovation. Considering the recommendations of [23], in particular on pp. 110-114, it will be essential regarding the implementation of regulatory measures. In addition to this, the benefits of formal standards, the New Approach and legislation, which adopts standards were demonstrated while [13] explained how labels can support innovation. Therefore, it is suggested to monitor the further development of the instruments suggested by this article and in particular to analyze how they contribute to innovation in the bioeconomy. Based on the findings of [16], it is recommended to analyze specifically, how regulations, in particular those relying on standards and Europe's "New Approach" can reduce uncertainty in transition markets.

Specific questions on the sustainability of selected bio-based automotive components, a possible establishment of a circular economy, as well as appropriate regulatory framework conditions in this context will be addressed in the above-mentioned project ConCirMy. Finally, it should be mentioned that our study could only include a limited number of interviewees and representatives of the various stakeholder groups in Europe. Therefore, more research is encouraged to deepen and extend the findings of this research.

Author Contributions: Conceptualization, S.W. and L.L.; methodology, S.W. and L.L.; data curation, S.W. and L.L.; investigation, S.W. and L.L.; validation, S.W. and L.L.; formal analysis, S.W.; writing—original draft, S.W. and L.L.; writing - review and editing, S.W. and L.L.; visualization, S.W and L.L.; funding acquisition, L.L. and S.W. All authors have read and agree to the published version of the manuscript.

Funding: This research was funded by the European Union's Horizon 2020 research and innovation program under grant agreement No. 727740 and in addition by Germany's research funding measure ReziProK, funding No. 033R236E.

Conflicts of Interest: The authors declare no conflict of interest.

\section{Appendix A. Information on the Ecolabels Analyzed for This Study}

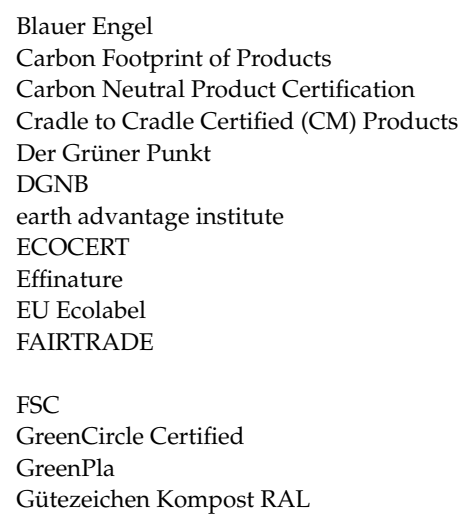

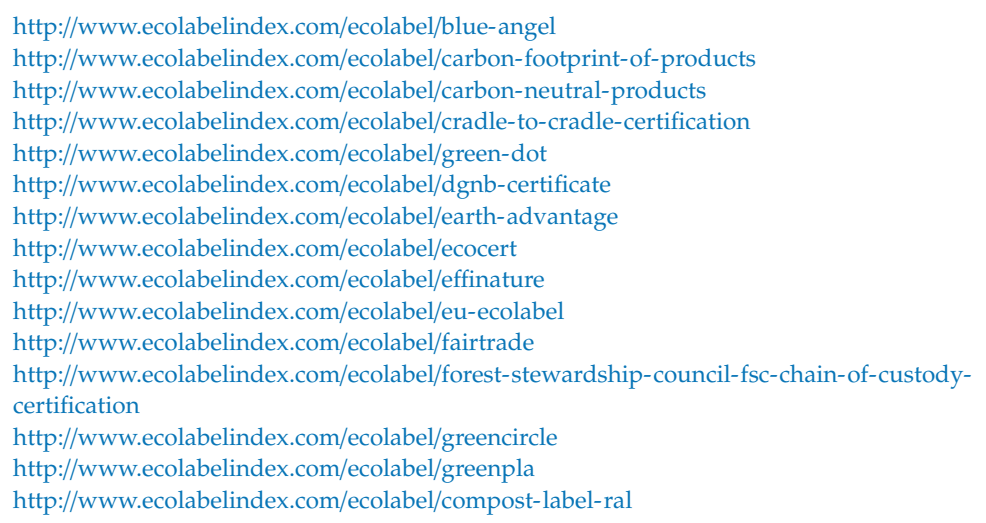




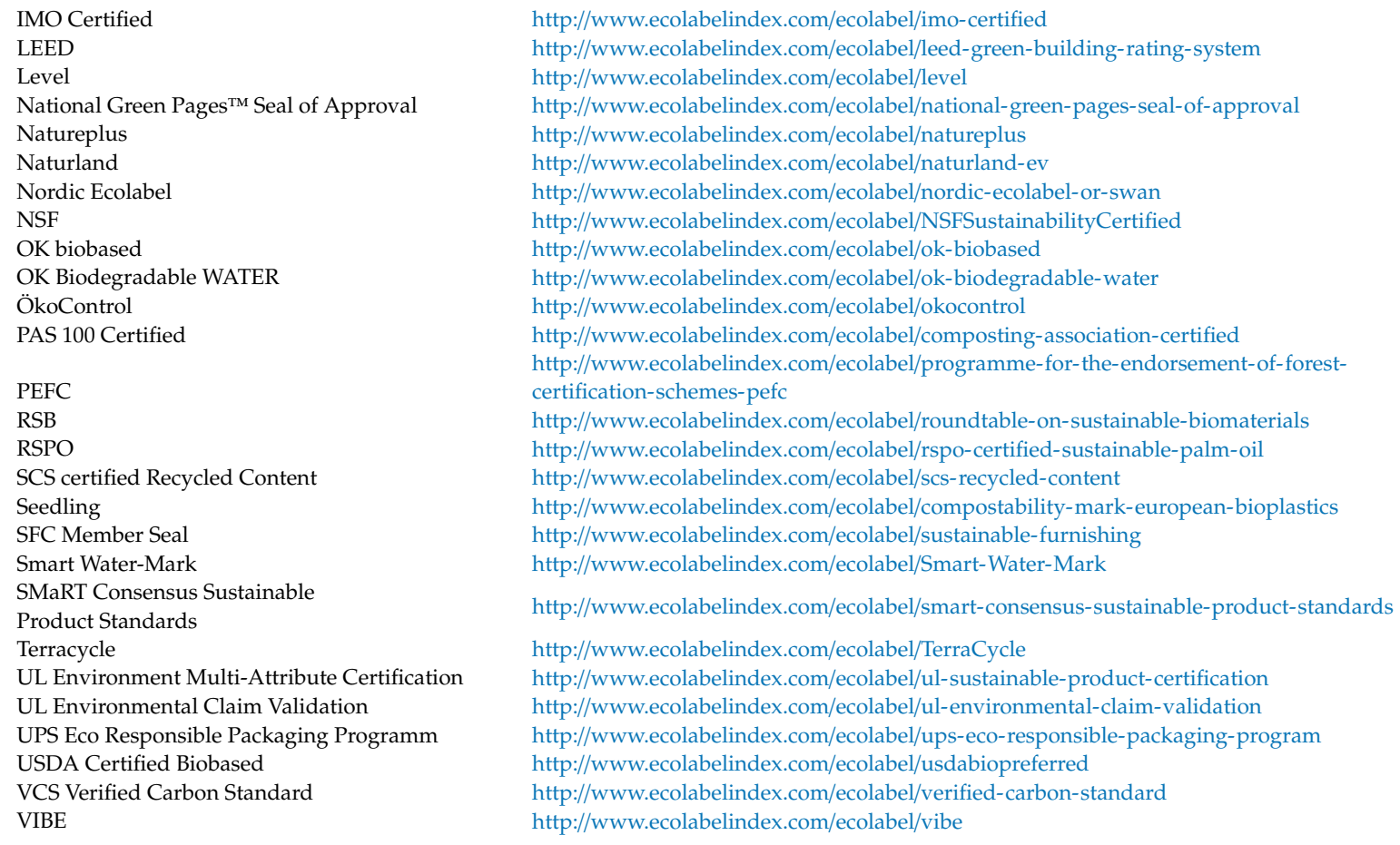

\section{References}

1. IfBB-Institut für Biokunststoffe und Bioverbundwerkstoffe. Hannover Messe: Niedersachsens Wissenschaftsminister Thümler Informiert Sich am Stand des IfBB; IfBB: Hannover, Germany, 2018.

2. Blain, B.L. Japan Proposes Wooden Cars Made of Plant-Based Cellulose Nanofibers. 2019. Available online: https://newatlas.com/automotive/cnf-cellulose-nanofibers-wooden-car/ (accessed on 27 December 2019).

3. Lanzini, P.F.; Testa, F.F. Iraldo, Factors affecting drivers' willingness to pay for biofuels: The case of Italy. J. Clean. Prod. 2016, 112, 2684-2692. [CrossRef]

4. STAR-ProBio. STAR-ProBio Deliverable D9.2, Recommendations for Standards and Criteria for Eco-Labels for Bio-Based Products. 2018. Available online: https://www.star-probio.eu (accessed on 21 October 2019).

5. Wurster, S.; Ladu, L. Bio-based Products-Suggestions for Ecolabel Criteria and Standards in Line with the Sustainable Development Goals. Int. J. Stand. Res. (IJSR) 2020, 17, 417-435.

6. CE Delft. Biobased Plastics in a Circular Economy Policy Suggestions for Biobased and Biobased Biodegradable Plastics. 2017. Available online: https://www.cedelft.eu/publicatie/biobased_plastics_ in_a_circular_economy/2022 (accessed on 29 November 2018).

7. Comité Européen de Normalisation. Bio-Based Products-Vocabulary; EN 16575:2014; CEN: Brussels, Belgium, 2014.

8. International Organization for Standardization. Traditional Chinese Medicine-Labelling Requirements of Products Intended for Oral or Topical Use; ISO 21371:2018; ISO: Geneva, Switzerland, 2018.

9. Organization for Economic Cooperation and Development. Eco-labels: The Industrialisation of Environmental Standards. Ecologist 1995, 25, 16-20.

10. Retail Forum for Sustainability. 2011. Available online: http://ec.europa.eu/environment/industry/retail/pdf/ labelling_issue\%20paper_final.pdf (accessed on 29 November 2018).

11. Organization for Economic Cooperation and Development. Effects of Eco-Labelling Schemes: Compilation of Recent Studies. 2005. Available online: http://www.oecd.org/officialdocuments/publicdisplaydocumentpdf/ ?doclanguage $=\mathrm{en} \& \mathrm{cote}=\mathrm{com} / \mathrm{env} / \mathrm{td}(2004) 34 /$ final (accessed on 29 November 2018).

12. Bröring, S.; Baum, C.M.; Butkowski, O.K.; Kircher, M. Kriterien für den Erfolg der Bioökonomie, in Bioökonomie für Einsteiger; Pietzsch, J., Ed.; Springer Spektrum: Berlin/Heidelberg, Germany, 2017.

13. Galarraga Gallastegui, I. The use of eco-labels: A review of the literature. Environ. Policy Gov. 2002, 12, 316-331. [CrossRef]

14. Fachagentur Nachwachsende Rohstoffe e.V. Umweltzeichen. 2019. Available online: https://beschaffung.fnr. de/umweltzeichen/ (accessed on 12 February 2020). 
15. International Organization for Standardization/International Electrotechnical Commission. Conformity Assessment_Vocabulary and General Principles; ISO/IEC 17000:2004; ISO: Geneva, Switzerland, 2004.

16. Blind, K.; Petersen, S.S.; Riillo, C.A.F. The impact of standards and regulation on innovation in uncertain markets. Res. Policy 2017, 46, 249-264. [CrossRef]

17. Blind, K.; Gauch, S. Research and Standardisation in Nanotechnology: Evidence from Germany. J. Technol. Transf. 2009, 34, 320-342. [CrossRef]

18. Comité Européen de Normalisation. CEN/TC 411-Bio-based Products. 2019. Available online: https://standards. cen.eu/dyn/www/f?p=204:7:0::::FSP_ORG_ID:874780\&cs=112703B035FC937E906D8EFA5DA87FAB8 (accessed on 29 November 2018).

19. European Commission. M/491 Mandate Addressed to CEN, CENELEC and ETSI for the Development of European Standards and Technical Specifications and/or Technical Re-ports for Bio-Surfactants and Bio-Solvents in Relation to Bio-Based Product Aspects. 2011. Available online: http://ec.europa.eu/growth/ tools-databases/mandates/index.cfm?fuseaction=search.detail\&id=476\# (accessed on 29 November 2018).

20. European Commission. M/492 Mandate Addressed to CEN, CENELEC and ETSI for the Development of Horizontal European Standards and other Standardisation Deliverables for Bio-Based Products. 2011. Available online: http://ec.europa.eu/growth/tools-databases/mandates/index.cfm?fuseaction=search.detail\& $\mathrm{id}=477 \#$ (accessed on 29 November 2018).

21. Ladu, L.; Blind, K. Overview of Policies, Standards and Certifications Supporting the European Bio-Based Economy. Curr. Opin. Green Sustain. Chem. 2017, 8, 30-35. [CrossRef]

22. Blind, K. The influence of regulations on innovation: A quantitative assessment for OECD countries. Res. Policy 2012, 41, 391-400. [CrossRef]

23. Porter, M.E.; van der Linde, C. Toward a new conception of the environment-competitiveness relationship. J. Econ. Perspect. 1995, 9, 97-118. [CrossRef]

24. Palmer, K.; Oates, W.E.; Portney, P.R. Tightening Environmental Standards: The Benefit-Cost or the No-Cost Paradigm? J. Econ. Perspect. 1995, 9, 119-132. [CrossRef]

25. Bosman, R.; Rotmans, J. Transition Governance towards a Bioeconomy: A Comparison of Finland and the Netherlands. Sustainability 2016, 8, 1017. [CrossRef]

26. Morone, P. Sustainability Transition towards a Biobased Economy: Defining, Measuring and Assessing. Sustainability 2018, 10, 2631. [CrossRef]

27. Comité Européen de Normalisation. New Approach and Other Directives. 2019. Available online: https://www.cen.eu/work/supportLegislation/Directives/Pages/default.aspx (accessed on 29 November 2018).

28. Pelkmans, J. The New Approach to Technical Harmonization and Standardization. J. Common Mark. Stud. 1987, 25, 249-269. [CrossRef]

29. CEN-CENELEC Annual Report CEN CENELEC 2013. 2013. Available online: https://www.cencenelec.eu/ News/Publications/Publications/AR2013_CEN_EN_final.pdf (accessed on 29 November 2018).

30. European Commission. A Sustainable Bioeconomy for Europe: Strengthening the Connection between Economy, Society and the Environment. Updated Bioeconomy Strategy. 2018. Available online: https:/ec.europa. eu/research/bioeconomy/pdf/ec_bioeconomy_strat-egy_2018.pdf\#view=fit\&pagemode=none (accessed on 29 November 2018).

31. STAR-ProBio STAR-ProBio Deliverable D9.1. Comprehensive Overview of Existing Regulatory and Voluntary Frameworks on Sustainability Assessment. 2018. Available online: http://www.star-probio.eu/wp-content/ uploads/2017/04/STAR-ProBio-D9.1_V-1.0.pdf (accessed on 29 November 2018).

32. European Parliament and the Council. Directive 2009/28/EC of the European Parliament and of the Council of 23 April 2009 on the promotion of the use of energy from renew-able sources and amending and subsequently repealing Directives 2001/77/EC and 2003/30/EC. Off. J. Eur. Union 2009, 5, 39-85.

33. European Parliament and the Council. Directive 2008/98/EC of the European Parliament and of the Council of 19 November 2008 on Waste and Repealing Certain Directives. 2008. Available online: https:/eur-lex.europa.eu/ legal-content/EN/TXT/HTML/?uri=CELEX:32008L0098\&from=EN (accessed on 29 November 2018).

34. Ecolabel Index. 2018. Available online: http://www.ecolabelindex.com/ (accessed on 29 November 2019).

35. Ladu, L.; Clavell, J.; Quitzow, R.; Costenoble, O.; Vrins, M.; van den Berg, J.; Babayan, T.; vom Berg, C.; Dammer, L.; Partanen, A.; et al. Policy paper on strategy for development of an RCS framework. Deliverable 3.3 of the STAR4BBI project. 2019. Available online: https:/www.star4bbi.eu/app/uploads/sites/11/2019/09/ D3.3-Sustainability-Certification-for-all-Products_final.pdf (accessed on 21 October 2019). 
36. Adams, W.C. Conducting Semi-Structured Interviews. In Newcomer: Handbook of Practical Program Evaluation; Wholey, K.J., Hatry, H., Eds.; Jossey-Bass: Hoboken, NY, USA, 2015; pp. 492-505.

37. European Commission. Energy. 2018. Available online: https://ec.europa.eu/energy/en/topics/renewa-bleenergy/biofuels/sustainability-criteria (accessed on 29 November 2018).

38. Federal Environment Agency (UBA). Nachhaltigkeitsstandards/Zertifizierung von Biomasse. 2018. Available online: https://www.umweltbundesamt.de/nachhaltigkeitsstandards-zertifizierung-von (accessed on 29 November 2018).

39. Open-Bio. Deliverable N ${ }^{\circ}$ 7.3: Proposal on eco-criteria for bio-based products. Public Summary. 2016. Available online: https://www.biobasedeconomy.eu/app/uploads/sites/2/2017/09/Open-Bio_D7-3_summary.pdf (accessed on 29 November 2018).

40. International Organization for Standardization. Plastics-Vocabulary; ISO 472:2013; ISO: Geneva, Switzerland, 2013.

41. Peuckert, J.; Quitzow, R. Acceptance of bio-based products on business-to-business markets and public procurement: Expert survey results. Biofuels Bioprod. Biorefin. 2017, 11, 92-109. [CrossRef]

42. TNS Political \& Social at the request of the European Commission-Directorate-General for Environment. Flash Eurobarometer 367 "Attitudes of Europeans towards Building the single market for green products". 2012. Available online: http://ec.europa.eu/environment/eurobarometers_en.htm (accessed on 29 November 2018).

43. Carus, M.; Dammer, L.; Puente, Á.; Raschka, A.; Arendt, O. Bio-Based Drop-in, Smart Drop-in and Dedicated Chemicals. 2017. Available online: https://www.roadtobio.eu/uploads/news/2017_October/RoadToBio_Dropin_paper.pdf (accessed on 29 November 2018).

44. Iffland, K. Definition, Calculation and Comparison of the "Biomass Utilization Efficiencies (BUE)" of Various Bio-based Chemicals, Polymers and Fuels. 2015. Available online: http://bio-based.eu/nova-papers/ (accessed on 29 November 2018).

45. STAR-ProBio. STAR-ProBio Deliverable D1.1, Report on Identified Environmental, Social and Economic Criteria/Indicators/Requirements and Related "Gap Analysis". 2017. Available online: www.star-probio.eu (accessed on 29 November 2018).

46. Vertech Group. Life Cycle Cost Assessment. 2014. CloseWEEE-WP8-DEL-D8.1-VTG-20150631-v02.doc. Available online: https://ec.europa.eu/research/participants/documents/downloadPublic?documentIds= 080166e5a0aca20f\&appId=PPGMS (accessed on 29 November 2018).

47. Fuller, S. Guidance on Life-Cycle Cost Analysis. Required by Executive Order 13123; Department of Energy, Federal Energy Management Program: Washington, DC, USA, 2005.

48. C2C (Cradle to Cradle Products Innovation Institute). Cradle to Cradle CertifiedTM. Product Standard Version 3.1. 2016. Available online: https://s3.amazonaws.com/c2c-web-site/resources/certification/standard/ STD_C2CCertified_ProductStandard_V3.1_082318.pdf (accessed on 29 November 2018).

49. Fachagentur Nachwachsende Rohstoffe e. V. Nachwachsende Rohstoffe im Einkauf, Themenheft III: Büro-Einrichtung, Material, Gestaltung. 2017. Available online: https://mediathek.fnr.de/broschuren/ nachwachsende-rohstoffe/nachhaltige-beschaffung.html (accessed on 29 November 2018).

50. European Commission. 4th Foresight Exercise Sustainable Agriculture, Forestry and Fisheries in the Bioeconomy-A Challenge for Europe. 2015. Available online: https://ec.europa.eu/research/scar/index.cfm? pg=foresight 4 th (accessed on 29 November 2018).

51. BBMG GlobeScan and SustainAbility. Re: Thinking Consumption-Consumers and the Future of Sustainability. 2012. Available online: https://globescan.com/rethinking-consumption-consumers-andthe-future-of-sustainability/ (accessed on 29 November 2018).

52. International Labour Organization. International Instruments and Corporate Social Responsibility a Booklet to Accompany Training on Promoting Labour Standards through Corporate Social Responsibility. 2007. Available online: https:/www.ilo.org/wcmsp5/groups/public/---ed_emp/---emp_ent/---multi/documents/ instructionalmaterial/wcms_227866.pdf (accessed on 29 November 2018).

53. Programme for the Endorsement of Forest Certification. Vom Wald zum Produkt. Die PEFC-Chain-OFCustody—So Funktioniert der Produktkettennachweis. Available online: https://pefc.de/media/filer_public/ 2d/38/2d385cb6-a7be-409a-8dfa-fb8e330b4a3e/tmppefc_coc-broschuere.pdf (accessed on 29 November 2018).

54. Environmental Investigation Agency. Who Watches the Watchman? Auditors and the Breakdown of Oversight in the RSPO. 2015. Available online: https://eia-international.org/wp-content/uploads/EIA-WhoWatches-the-Watchmen-FINAL.pdf (accessed on 29 November 2018). 
55. Comité Européen de Normalisation. Plastics_Determination of Bio-Based Carbon Content; CEN/TS 16137:2011; CEN: Brussels, Belgium, 2011.

56. International Organization for Standardization. ISO 14044 Environmental Management-Life Cycle Assessment_-Requirements and Guidelines; ISO: Geneva, Switzerland, 2006.

57. Comité Européen de Normalisation. Bio-based products_Life Cycle Assessment; EN 16760:2015; ISO: Geneva, Switzerland, 2015.

58. Wurster, S.; Ladu, L.; Majer, S. Förderung biobasierter Produkte durch Normung und Zertifizierung. Horizon-2020-Projekt STAR-ProBio-Bisher Erreichtes, Handlungsbedarf und Lösungsansätze. DIN Mitt. 2018, 2018, 13-21.

59. Görmer, M. Harmonisierung von Ökobilanzregeln für Biobasierte Werkstoffe. IfBB-Webinarreihe: “Biowerkstoffe im Fokus!”. 2018. Available online: https://www.ifbb-hannover.de/files/IfBB/downloads/ webinarreihe/20180816_Webinar_23_Harmonisierung_von_Oekobilanzregeln_fuer_biobasierte_ Werkstoffe.pdf (accessed on 29 November 2018).

60. Nessi, S.; Bulgheroni, C.; Konti, A.; Sinkko, T.; Tonini, D.; Pant, R. Environmental Sustainability Assessment Comparing through the Means of Lifecycle Assessment the Potential Environmental Impacts of the Use of Alternative Feedstock (Biomass, Recycled Plastics, CO2) for Plastic Articles in Comparison to Using Current Feedstock (Oil and Gas). 2018. Available online: https://eplca.jrc.ec.europa.eu/permalink/PLASTIC_LCI/ Plastic_LCA_Report_I_2018.11.20.pdf (accessed on 29 November 2018).

61. United States Department of Agriculture. Biopreferred. 2018. Available online: https://www.biopreferred. gov/ (accessed on 29 November 2018).

(C) 2020 by the authors. Licensee MDPI, Basel, Switzerland. This article is an open access article distributed under the terms and conditions of the Creative Commons Attribution (CC BY) license (http://creativecommons.org/licenses/by/4.0/). 